\title{
Correlating electronic and magnetic coupling in large magnetic molecules via scanning tunneling microscopy
}

\author{
Judith Donner, ${ }^{1,2}$ Jan-Philipp Broschinski, ${ }^{3}$ Bastian Feldscher, ${ }^{3}$ Anja Stammler, ${ }^{3}$ \\ Hartmut Bögge, ${ }^{3}$ Thorsten Glaser, ${ }^{3, *}$ and Daniel Wegner ${ }^{1,2, \dagger}$ \\ ${ }^{1}$ Institute for Molecules and Materials, Radboud University, Heyendaalseweg 135, 6525 AJ Nijmegen, Netherlands \\ ${ }^{2}$ Physikalisches Institut and Center for Nanotechnology, Westfälische Wilhelms-Universität Münster, 48149 Münster, Germany \\ ${ }^{3}$ Lehrstuhl für Anorganische Chemie I, Fakultät für Chemie, Universität Bielefeld, Universitätsstrasse 25, 33615 Bielefeld, Germany
}

(Received 4 August 2016; revised manuscript received 30 March 2017; published 24 April 2017)

\begin{abstract}
In an effort to improve the spin coupling in single-molecule magnets, we rationally designed a new buildingblock molecule with significantly enhanced spin coupling compared to a previously established molecule. We relate this to a stabilization of aromaticity in the central connecting carbon ring, promoting the spin-polarization mechanism. This correlation between magnetic and electronic properties is supported by bulk measurements as well as submolecularly resolved scanning tunneling microscopy and spectroscopy experiments, where we found distinct differences in the local density of states distribution of the two molecules, especially at the central carbon ring. While the established molecule exhibits localized, spatially decoupled and even switchable states, the improved building block exhibits symmetric local density of states delocalized over the entire molecule, also revealing that this main characteristic electronic property is preserved upon adsorption on a metal surface. Due to their planar geometry, these molecules can serve as model systems for scanning-probe based studies of molecular magnetism.
\end{abstract}

DOI: 10.1103/PhysRevB.95.165441

\section{INTRODUCTION}

Single-molecule magnets (SMMs) exhibit a slow relaxation of the magnetization at low temperatures [1]. This phenomenon has attracted increasing attention over the last two decades [2-7] and fueled speculations on many potential applications [8-10]. However, most potential applications are thought to require the slow relaxation at higher temperatures as well as a controlled deposition on conductive surfaces (i.e., electrode contacts) with single-molecule addressability [11-14]. Besides practical difficulties for a controlled deposition of SMMs on surfaces [15], studies on various molecular magnetic systems like the archetype SMM $\mathrm{Mn}_{12}$ [16,17], or on transition-metal phthalocyanines and porphyrins [18-21], showed that the surface can significantly alter the SMM properties via hybridization, charge transfer, and ligand-field modifications. This can improve but also destroy SMM properties, as is the case for $\mathrm{Mn}_{\mathbf{1 2}}$. Understanding these influences calls for careful studies of adsorbed SMMs, for which scanning tunneling microscopy (STM) and spectroscopy (STS) are ideally suited $[13,22]$.

We have recently developed the ligand triplesalen [Fig. 1(a)] for the rational synthesis of a new family of heptanuclear SMMs $\left[\mathrm{Mn}_{6}^{\mathrm{III}} \mathrm{M}^{\mathrm{III}}\right]^{3+}\left(\mathrm{M}=\mathrm{Cr}^{\mathrm{III}}, \mathrm{Mn}^{\mathrm{III}}\right)[23,24]$. The central unit phloroglucinol $(=1,3,5$-trihydroxybenzene) has been chosen as an $m$-phenylene coupling unit for ferromagnetic interactions by the spin-polarization mechanism. Briefly, the magnetic moments at the metal ions polarize the electron density of a delocalized $\pi$ system so that the spin density alternates in sign for neighboring atoms [as illustrated by arrows in Fig. 1(a)]. This permits the electronic interaction of the metal ions, and hence the spin coupling, even over

\footnotetext{
*tglaser@uni-bielefeld.de

†d.wegner@science.ru.nl
}

large distances. For this spin-polarization mechanism to work efficiently, the presence of a delocalized $\pi$-electron system in the central carbon ring, akin to benzene, should be a key ingredient. Unfortunately, magnetic measurements of the building block $\left[\left(\operatorname{talen}^{t-\mathrm{Bu}_{2}}\right) \mathrm{M}_{3}\right]$ revealed that for $\mathrm{M}=\mathrm{Cu}^{\mathrm{II}}$, the ferromagnetic coupling between the metal ions is relatively weak [25]. This leads to non-well-stabilized spin ground states, counterproductive for SMMs [26]. Improving the spin coupling in these molecular building blocks would thus be a rational strategy to optimize in our $\left[\mathrm{Mn}_{6}^{\mathrm{III}} \mathrm{M}^{\mathrm{III}}\right]^{3+}$ SMMs.

In order to understand why the triplesalen ligand does not efficiently promote ferromagnetic interactions by the spin-polarization mechanism, we analyzed spectroscopic and structural features of our compounds carefully and found that the triplesalen complexes cannot only be described by purely aromatic resonance structures but also by a nonaromatic heteroradialene resonance structure [see Fig. 1(b)]. This has no delocalized central carbon ring to promote the interaction between the three metal subunits, preventing an effective spin polarization [27]. As this heteroradialene can only be formed in the presence of unsaturated $\mathrm{C}=\mathrm{N}$ imine groups [highlighted in red in Fig. 1(b)], a rational improvement would be the replacement of the unsaturated $\mathrm{C}=\mathrm{N}$ imine bonds by saturated $\mathrm{C}-\mathrm{N}$ amine bonds. This design results in the new triplesalalen ligand $\mathrm{H}_{6}$ talalen ${ }^{t-\mathrm{Bu}_{2}}$.

Herein we present our combined efforts to find evidence between the correlation of magnetic coupling and the electronic structure in our triplesalen-based SMM building blocks, with the goal of strengthening the ferromagnetic interactions, by a combination of bulk measurements as well as STM-based single-molecule experiments. We describe the synthesis of the new triplesalalen ligand $\mathrm{H}_{6}$ talalen ${ }^{t-\mathrm{Bu}_{2}}$ and its complex [(talalen $\left.\left.{ }^{t-\mathrm{Bu}_{2}}\right) \mathrm{Cu}_{3}^{\mathrm{II}}\right]$ [Fig. 1(c)] with no heteroradialene character and improved magnetic coupling, as revealed by single-crystal x-ray diffraction, NMR, UV-vis, and FTIR spectroscopy as well as SQUID magnetometry on crystalline 

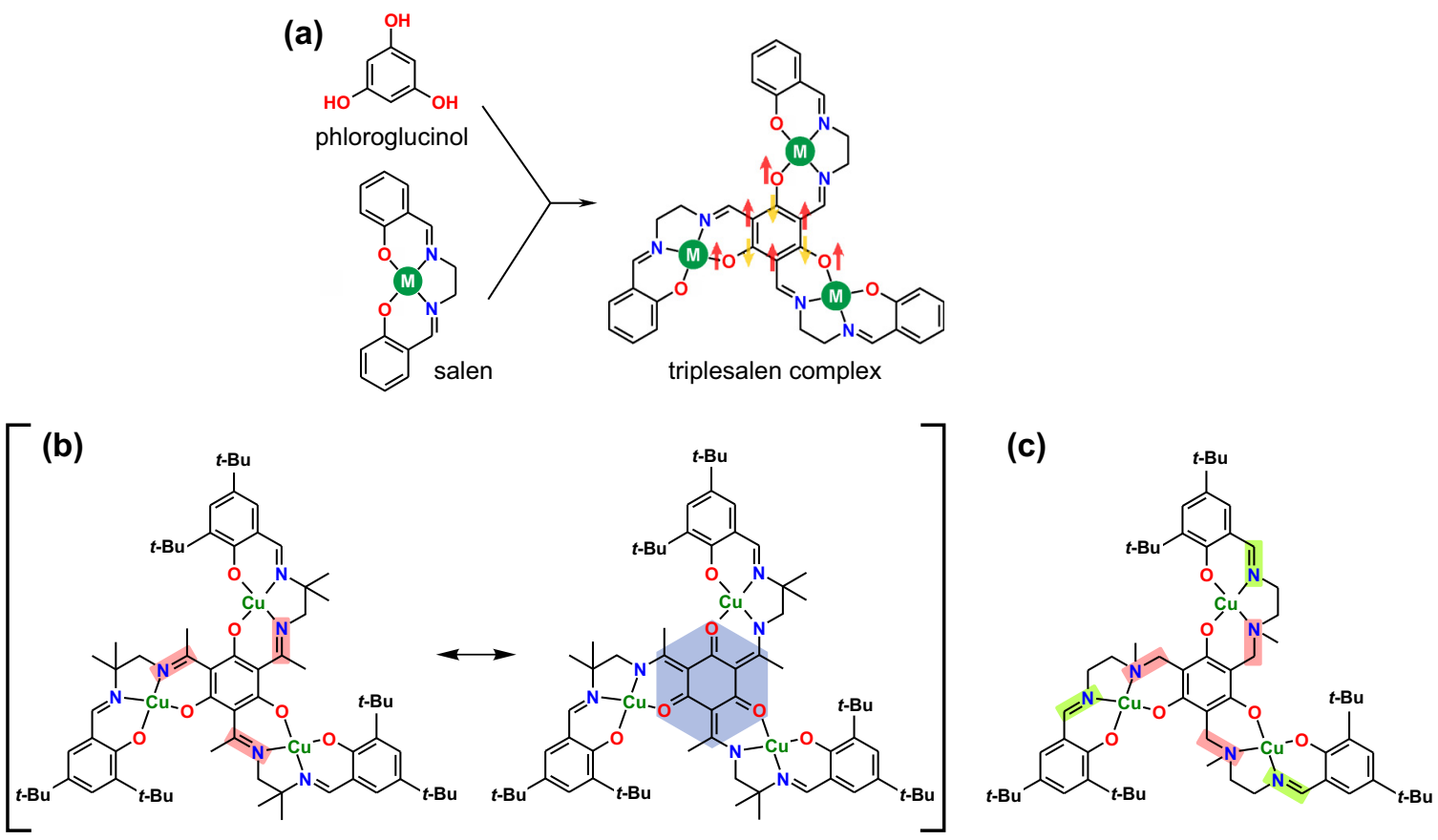

FIG. 1. (a) Schematics of the SMM rational design principle: a $m$-phenylene coupling unit (ferromagnetic coupling) combined with a salen ligand (magnetic anisotropy) results in the triplesalen complex with ferromagnetic coupling of the metallic spin centers via the spin-polarization mechanism (indicated by arrows). (b) The electronic structure of the central carbon ring in $\left[\left(\operatorname{talen}^{t-\mathrm{Bu}_{2}}\right) \mathrm{Cu}_{3}^{\mathrm{II}}\right]$ must be described by two resonance structures, an aromatic (left) and a nonaromatic heteroradialene (right, highlighted in blue) as determined recently [28,29]. (c) The electronic structure of $\left[\left(\operatorname{talalen}^{t-\mathrm{Bu}_{2}}\right) \mathrm{Cu}_{3}^{\mathrm{II}}\right]$ is described only by the aromatic resonance structure. The change from an unsaturated $\mathrm{C}=\mathrm{N}$ imine $(\mathrm{b})$ to saturated $\mathrm{C}-\mathrm{N}$ amine bonds (c) is highlighted in red, the remaining labile terminal imine bonds in green.

samples, and supported by DFT calculations. We also deposited single molecules of the established [(talen $\left.\left.{ }^{t-\mathrm{Bu}_{2}}\right) \mathrm{Cu}_{3}^{\mathrm{II}}\right]$ and the new $\left[\left(\right.\right.$ talalen $\left.\left.^{t-\mathrm{Bu}_{2}}\right) \mathrm{Cu}_{3}^{\mathrm{II}}\right]$ complex on a $\mathrm{Au}(111)$ surface in order to compare their structural and electronic properties with submolecular spatial resolution using STM/STS. We found distinct differences in the local density of states of the two molecules, especially at the central carbon ring, which are compatible with the different degrees of electronic coupling. This supports that the rational improvement of the magnetic coupling in the new building block stems from an improved intramolecular electronic coupling, which is obviously preserved upon adsorption on $\mathrm{Au}(111)$. Thus, combining the rational improvement of our ligand system with the surface deposition and single-molecule addressability provides a further step towards fundamental understanding of SMMs. Due to their planar molecular structure, every part of the molecule can be accessed with the scanning probe, making them ideal candidates to study molecular magnetism with submolecular resolution, as has been demonstrated recently on a distantly related molecule [28].

\section{RESULTS AND DISCUSSION}

\section{A. Synthesis and chemical characterization}

We have established a new synthetic pathway for the triplesalalen ligand $\mathrm{H}_{6}$ talalen ${ }^{t-\mathrm{Bu}_{2}}$. The synthesis of this ligand and its complex [(talalen $\left.\left.{ }^{t-\mathrm{Bu}_{2}}\right) \mathrm{Cu}_{3}\right]$ is described in detail in the Supplemental Material [29]. We note that during the synthesis and crystallization, we observed fragmentation, demonstrating that the remaining terminal imine groups of
$\mathrm{H}_{6}$ talalen $^{t-\mathrm{Bu}_{2}}$ [Fig. 1(c)] are unstable towards hydrolysis even in the complexed form. Importantly, results from NMR, FTIR, and optical spectroscopies as well as single-crystal $\mathrm{x}$-ray diffraction confirm that neither the triplesalalen ligand nor the complex exhibit heteroradialene character. A detailed discussion of the evaluation of heteroradialene character can be found in the Supplemental Material [29].

\section{B. Magnetic characterization}

Temperature-dependent measurements of the magnetic susceptibility of $\left[\left(\right.\right.$ talalen $\left.\left.^{t-\mathrm{Bu}_{2}}\right) \mathrm{Cu}_{3}^{\mathrm{II}}\right]$ were performed for various samples at different magnetic fields. Figure 2(a) shows a representative example together with that of the heteroradialene [( $\left.\left.\operatorname{talen}^{t-\mathrm{Bu}_{2}}\right) \mathrm{Cu}_{3}^{\mathrm{II}}\right]$ [25] for comparison. The effective magnetic moment $\mu_{\mathrm{eff}}=3.18 \mu_{\mathrm{B}}$ at $290 \mathrm{~K}$ corresponds to the calculated value for three noninteracting $\mathrm{Cu}^{\mathrm{II}}$ ions $\left(\mu_{\text {eff }}=\right.$ $3.17 \mu_{\mathrm{B}}, g=2.11$ ). With decreasing temperature, $\mu_{\text {eff }}$ starts to increase slightly and more steeply below $50 \mathrm{~K}$. This behavior indicates ferromagnetic interactions between the three $\mathrm{Cu}^{\mathrm{II}}$ ions. We simulated the temperature dependence of $\mu_{\text {eff }}$ with the appropriate spin-Hamiltonian:

$$
H=-2 J\left(\mathbf{S}_{1} \mathbf{S}_{2}+\mathbf{S}_{2} \mathbf{S}_{3}+\mathbf{S}_{1} \mathbf{S}_{3}\right)+\sum_{i=1}^{3}\left(g_{i} \mu_{B} S_{i} B\right)
$$

for an equilateral $\mathrm{Cu}_{3}^{\mathrm{II}}\left(S_{i}=1 / 2\right)$ triangle by a full-matrix diagonalization approach including Heisenberg-Dirac-van Vleck (HDvV) exchange and Zeeman interactions using the JulX software package [30] that accounts for saturation 

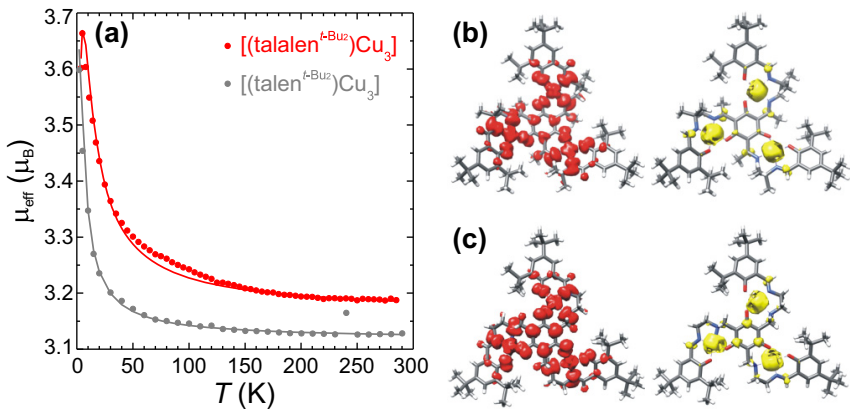

FIG. 2. (a) Temperature dependence of the effective magnetic moment, $\mu_{\mathrm{eff}}$, of $\left[\left(\right.\right.$ talalen $\left.\left.^{t-\mathrm{Bu}_{2}}\right) \mathrm{Cu}_{3}^{\mathrm{II}}\right]$ at $1 \mathrm{~T}$ (red). The solid line corresponds to the fit with $J=3.75 \mathrm{~cm}^{-1}, g=2.11, \chi_{\mathrm{TIP}}=496 \times$ $10^{-6} \mathrm{~cm}^{3} \mathrm{~mol}^{-1}$, and $\Theta_{\mathrm{w}}=-0.8 \mathrm{~K}$. For comparison, the corresponding plot of $\left[\left(\operatorname{talen}^{t-\mathrm{Bu}_{2}}\right) \mathrm{Cu}_{3}^{\mathrm{II}}\right]$ is shown in gray $\left(J=1.17 \mathrm{~cm}^{-1}\right.$, $g=2.078, \chi_{\mathrm{TIP}}=380 \times 10^{-6} \mathrm{~cm}^{3} \mathrm{~mol}^{-1}$, and $\left.\Theta_{\mathrm{w}}=-0.07 \mathrm{~K}\right)$ [25]. (b) Positive (left) and negative (right) spin-density plots of $\left[\left(\operatorname{talen}^{t-\mathrm{Bu}_{2}}\right) \mathrm{Cu}_{3}^{\mathrm{II}}\right]$ as obtained from DFT calculations (see Supplemental Material [31] for details). (c) Spin-density plots of $\left[\left(\right.\right.$ talalen $\left.\left.^{t-\mathrm{Bu}_{2}}\right) \mathrm{Cu}_{3}^{\mathrm{II}}\right]$.

effects. Intermolecular interactions are modeled by a Weiss correction $\Theta_{\mathrm{w}}$. Fitted values of $\chi_{\text {TIP }}$ are subtracted from the simulated and experimental data. The best agreement between the experimental and simulated data was obtained for $J=3.75 \mathrm{~cm}^{-1}, g=2.11, \chi_{\mathrm{TIP}}=496 \times 10^{-6} \mathrm{~cm}^{3} \mathrm{~mol}^{-1}$, and $\Theta_{\mathrm{w}}=-0.8 \mathrm{~K}$. In comparison, the coupling constant for $\left[\left(\operatorname{talen}^{t-\mathrm{Bu}_{2}}\right) \mathrm{Cu}_{3}^{\mathrm{II}}\right]$ is $1.17 \mathrm{~cm}^{-1}$ [25]. Thus, as intended, the ferromagnetic coupling is stronger in [(talalen $\left.\left.{ }^{t-\mathrm{Bu}_{2}}\right) \mathrm{Cu}_{3}^{\mathrm{II}}\right]$. This three times larger ferromagnetic coupling is ascribed to the improved spin polarization via the delocalized central unit due to the absence of heteroradialene character.

In order to support this interpretation, we performed DFT calculations on both $\left[\left(\right.\right.$ talalen $\left.\left.^{t-\mathrm{Bu}_{2}}\right) \mathrm{Cu}_{3}^{\mathrm{II}}\right]$ and $\left[\left(\operatorname{talen}^{t-\mathrm{Bu}_{2}}\right) \mathrm{Cu}_{3}^{\mathrm{II}}\right]$ (see the Supplemental Material [31]). Figure 2(c) shows the characteristic alternating positive/negative spin density for spin polarization in the central phloroglucinol ring for $\left[\left(\right.\right.$ talalen $\left.\left.^{t-\mathrm{Bu}_{2}}\right) \mathrm{Cu}_{3}^{\mathrm{II}}\right]$. In contrast, the heteroradialenelike $\left[\left(\operatorname{talen}^{t-\mathrm{Bu}_{2}}\right) \mathrm{Cu}_{3}^{\mathrm{II}}\right]$ possesses only a minor negative spin density $\left(-2 \times 10^{-3}\right.$ vs $-31 \times 10^{-3}$ arb. units $)$ in the central ring [Fig. 2(b)]. This supports that the molecular orbitals close to LUMO and HOMO are not as effectively delocalized over the central ring in the nonaromatic heteroradialene unit in $\left[\left(\operatorname{talen}^{t-\mathrm{Bu}_{2}}\right) \mathrm{Cu}_{3}^{\mathrm{II}}\right]$, thereby weakening the spin coupling.

\section{STM/STS single-molecule characterization}

Such a significantly different character of the central carbon ring should be reflected in the electronic structure, i.e., the local density of states (LDOS) of the molecules, and STM/STS is ideally suited to test this. Therefore, we deposited the complexes [(talen $\left.\left.{ }^{t-\mathrm{Bu}_{2}}\right) \mathrm{Cu}_{3}\right]$ and [(talalen $\left.{ }^{t-\mathrm{Bu}_{2}}\right) \mathrm{Cu}_{3}$ onto a clean $\mathrm{Au}(111)$ surface for a direct structural and electronic characterization of the adsorbed molecule. To lift the central part of the molecule off the surface and thereby reduce the interaction with the substrate, we used bulky tert-butyl groups for both complexes [32,33]. Unfortunately, a standard thermal sublimation was not feasible due to the fragility of these large complexes. We therefore utilized a pulse-injection technique for a clean in situ deposition of the molecules, which we have
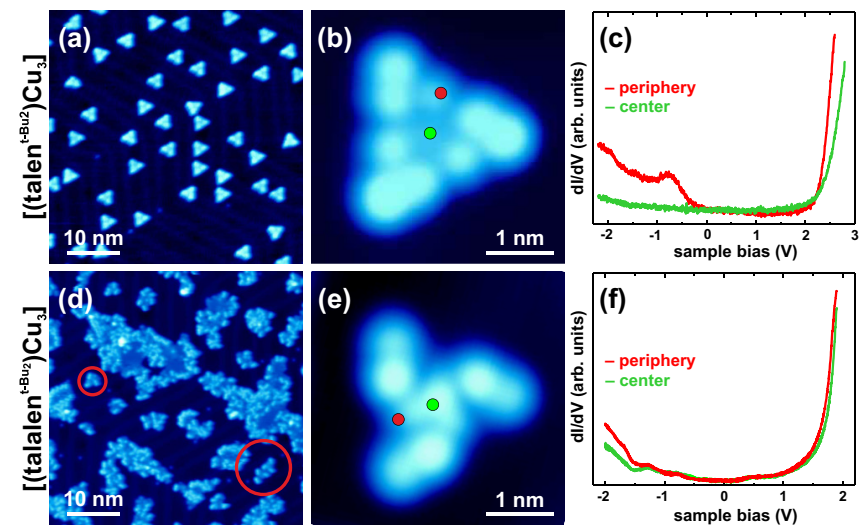

FIG. 3. Pulse-injection deposition of $\left[\left(\operatorname{talen}^{t-\mathrm{Bu}_{2}}\right) \mathrm{Cu}_{3}\right]$ leads to clean samples with intact isolated molecules exhibiting a characteristic triangular shape (a) and (b), while [(talalen $\left.\left.{ }^{t-\mathrm{Bu}_{2}}\right) \mathrm{Cu}_{3}\right]$ tends to dissociate, leaving islands of fragments and solvent molecules (d) but also unbroken single molecules [marked circles in (d) and (e)]. Comparison of $d I / d V$ spectra in the molecular center vs periphery reveal a spatially highly inhomogeneous LDOS for $\left[\left(\operatorname{talen}^{t-\mathrm{Bu}_{2}}\right) \mathrm{Cu}_{3}\right]$ (c), while no qualitative difference is found for [(talalen $\left.\left.{ }^{t-\mathrm{Bu}_{2}}\right) \mathrm{Cu}_{3}\right]$ (f). Note that spectra taken on equivalent positions of the salen arms look identical; hence for simplicity we only show one spectrum. Apparent heights are voltage dependent and in the range of $0.27-0.41 \mathrm{~nm}$ for [(talen $\left.{ }^{t-\mathrm{Bu}_{2}}\right) \mathrm{Cu}_{3}$ ] and $0.25-0.31 \mathrm{~nm}$ for [ $\left(\right.$ talalen $\left.^{t-\mathrm{Bu}_{2}}\right) \mathrm{Cu}_{3}$ ]. [Imaging parameters: $1 \mathrm{~V}, 50 \mathrm{pA} ; 49 \times 49 \mathrm{~nm}^{2}$ (a) and (c), $3.7 \times 3.7 \mathrm{~nm}^{2}$ (b) and (d).]

reported earlier [15]. After the preparation, the sample was immediately transferred into the cryogenic STM (operated at $T=5 \mathrm{~K}$ ) and topography images were taken to identify single molecules and to acquire local tunneling spectra $(d I / d V$ vs $V$, open feedback) as well as spectroscopic maps ( $d I / d V$ vs position, constant-current mode). In first approximation, $d I / d V$ reflects the LDOS, where negative (positive) voltages correspond to (un)occupied states, and $V=0$ defines the Fermi energy $\left(E_{F}\right)$. Details of the sample preparation and STM/STS characterization have been published previously [15,34].

Figure 3 presents STM images of both molecules on $\mathrm{Au}(111)$. The topography of $\left[\left(\operatorname{talen}^{t-\mathrm{Bu}_{2}}\right) \mathrm{Cu}_{3}\right]$ [Fig. 3(a)] shows threefold-symmetric adsorbates that are equally distributed over the surface. The adsorbates lie mostly in the fcc regions and elbow sites of the $\mathrm{Au}(111)$ herringbone reconstruction. We do not observe any other adsorbates on the surface, which speaks for a clean sample preparation obtained by the pulse-injection technique. A highly resolved topography image of a single [(talen $\left.\left.{ }^{t-\mathrm{Bu}_{2}}\right) \mathrm{Cu}_{3}\right]$ molecule [Fig. 3(b)] reveals nine lobes with different intensities surrounding a depression in the molecular center. Comparison of the adsorbates with the chemical structure [see Fig. 4(a)] allows for identification of submolecular parts and reveals that the molecules are intact. The topography is dominated by the six bulky tertbutyl and the three methyl groups [32,33]. In contrast, the overview image of [(talalen $\left.{ }^{t-\mathrm{Bu}_{2}}\right) \mathrm{Cu}_{3}$ ] molecules [Fig. 3(d)] exhibits many different structures on the surface, mostly irregular and disordered clusters and islands of different sizes. This is consistent with the mentioned hydrolytic instability of the terminal imine groups. Nevertheless, we regularly found threefold-symmetric adsorbates on the bare $\mathrm{Au}(111)$ 

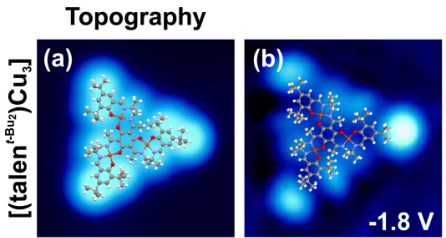

dl/dV maps
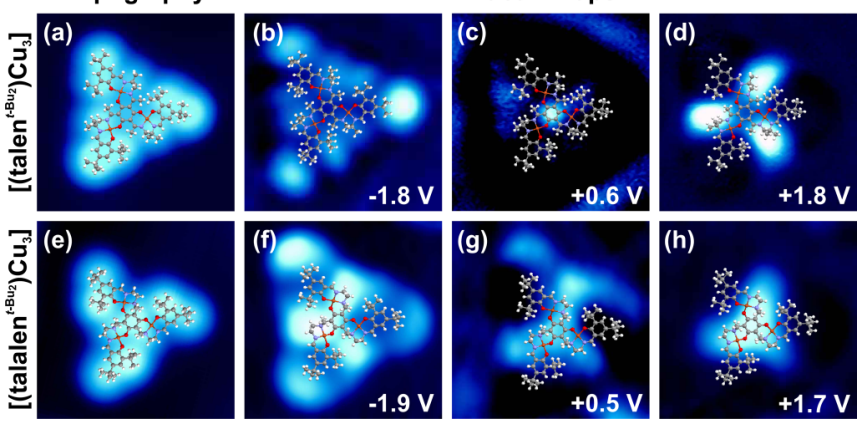

FIG. 4. (a) STM image of a single $\left[\left(\operatorname{talen}^{t-\mathrm{Bu}_{2}}\right) \mathrm{Cu}_{3}\right]$ molecule with its molecular structure overlaid, (b)-(d) corresponding $d I / d V$ maps. (e) STM image of a single [(talalen $\left.\left.{ }^{t-\mathrm{Bu}_{2}}\right) \mathrm{Cu}_{3}\right]$ molecule, and (f)-(h) corresponding $d I / d V$ maps. We find a clear difference in the orbital distribution, especially when focusing on the central carbon ring that connects the three salen subunits. Image sizes: $3.7 \times 3.7 \mathrm{~nm}^{2}$. All $d I / d V$ maps were taken at a set-point current of $50 \mathrm{pA}$ using lock-in detection (modulation voltage $20 \mathrm{mV}_{\mathrm{rms}}$, frequency $\approx 750 \mathrm{~Hz}$ ).

surface in between these islands. Close-up views of these adsorbates [Fig. 3(e)] and a comparison with the chemical structure [Fig. 4(e)] again reveal that these [(talalen $\left.\left.{ }^{t-\mathrm{Bu}_{2}}\right) \mathrm{Cu}_{3}\right]$ molecules are intact.

Despite a certain degree of reminiscence, a direct comparison of the topography features between [ $\left.\left(\operatorname{talen}^{t-\mathrm{Bu}_{2}}\right) \mathrm{Cu}_{3}\right]$ and $\left[\left(\right.\right.$ talalen $\left.\left.^{t-\mathrm{Bu}_{2}}\right) \mathrm{Cu}_{3}\right]$ already shows significant distinctions, regardless of the fact that the molecular structures have only seemingly subtle differences. For a more thorough analysis of the molecular electronic properties, we performed STS measurements. $d I / d V$ spectra of $\left[\left(\operatorname{talen}^{t-\mathrm{Bu}_{2}}\right) \mathrm{Cu}_{3}\right][$ Fig. 3(c)] reveal that the LDOS is strongly site dependent. While the spectrum in the molecular center (green curve) is more or less featureless between -2 and $+2 \mathrm{~V}$, we observe an occupied state at about $-0.7 \mathrm{~V}$ on the molecular periphery (red curve), and the $d I / d V$ intensity above $+2 \mathrm{~V}$ increases faster. In contrast, the $d I / d V$ spectra of $\left[\left(\right.\right.$ talalen $\left.\left.^{t-\mathrm{Bu}_{2}}\right) \mathrm{Cu}_{3}\right]$ [Fig. 3(f)] are almost identical with no qualitative differences in the center vs the periphery. Hence, the different spectroscopic site dependence of the $d I / d V$ spectra of $\left[\left(\operatorname{talen}^{t-\mathrm{Bu}_{2}}\right) \mathrm{Cu}_{3}\right]$ vs [( talalen $\left.\left.^{t-\mathrm{Bu}_{2}}\right) \mathrm{Cu}_{3}\right]$ gives a first indication that they exhibit quite different electronic properties, despite the subtle structural differences.

In order to better understand the spatial distribution of the LDOS, we performed STS-based energy-dependent spectroscopic mapping. In brief, these $d I / d V$ maps reflect the spatial LDOS distribution at the selected voltage, which essentially allows for imaging molecular orbitals (i.e., $|\Psi|^{2}$ ) [35,36]. We found clear resonances in both the occupied and unoccupied energy regions, as summarized in the $d I / d V$ maps shown in Fig. 4 (cf. Supplemental Material [34] for a complete set of $d I / d V$ maps). For [( $\left.\left.\operatorname{talen}^{t-\mathrm{Bu}_{2}}\right) \mathrm{Cu}_{3}\right]$, maps in the occupied energy region show lobes at each of the tert-butyl and methyl groups [Fig. 4(b)], whereas the molecular center (i.e., the location of the central carbon ring) exhibits no intensity over the entire accessible occupied energy range. In contrast, within an energy window $0.6-1.2 \mathrm{eV}$ above $E_{F}$ we found a pronounced intensity localized exclusively on the central carbon ring, while the rest of the molecule remains dark [Fig. 4(c)]. Only above
$1.2 \mathrm{eV}$, when the central feature starts to disappear, additional intensity arises along the lateral edges of the triangular molecule, thus forming a windmill-like pattern Fig. 4(d)]. This latter feature remains visible even above $2 \mathrm{eV}$, where it becomes a very strong resonance. Overall, there is only a very small energy region $\left(E-E_{\mathrm{F}}=1.2-1.4 \mathrm{eV}\right)$ where we observed simultaneous intensity on the central and other parts of the molecule, but the voltage dependence of all observed features leads us to conclude that this is only due to an energetic overlap of two different molecular orbitals. We note that the lateral extension of the central spectroscopic feature whenever it appears dim (approximately 5-6 $\AA$ ) is too large to be explained by a node of an extended molecular orbital. Hence, our analysis of the observed different energy dependences and spatial extensions of LDOS maps leads us to conclude that the central carbon ring seems to be mostly electronically decoupled from the rest of the molecule, in accordance with the expected heteroradialene character of this complex.

In comparison, $d I / d V$ maps of $\left[\left(\right.\right.$ talalen $\left.\left.^{t-\mathrm{Bu}_{2}}\right) \mathrm{Cu}_{3}\right]$ reveal a different behavior. For all voltages in the occupied region, there is always LDOS intensity at the central carbon ring as well as the periphery of the triangular molecule [Fig. 4(f)]. The differences are even better visible in the unoccupied region: for $E-E_{\mathrm{F}}>0.3 \mathrm{eV}$, we observed the windmill-like pattern but also here we found a simultaneous high intensity at the central ring [Fig. 4(g)]. Similar to [(talen $\left.\left.{ }^{t-\mathrm{Bu}_{2}}\right) \mathrm{Cu}_{3}\right]$, this feature becomes a very strong resonance above $2 \mathrm{eV}$, but again the LDOS also remains on the molecular center [Fig. 4(h)]. Overall, the comparison between $\left[\left(\operatorname{talen}^{t-\mathrm{Bu}_{2}}\right) \mathrm{Cu}_{3}\right]$ and $\left[\left(\right.\right.$ talalen $\left.\left.^{t-\mathrm{Bu}_{2}}\right) \mathrm{Cu}_{3}\right]$ reveals that the changes in the molecular structure do not affect the outer tert-butyl phenol groups, but the electronic structure changes drastically on the central part of the molecule, i.e., the part that is decisive for the electronic coupling within the SMM building block. Most importantly, for [(talalen $\left.\left.{ }^{t-\mathrm{Bu}_{2}}\right) \mathrm{Cu}_{3}\right]$ all observed maps also involve LDOS at the central carbon ring, whereas in the case of $\left[\left(\operatorname{talen}^{t-\mathrm{Bu}_{2}}\right) \mathrm{Cu}_{3}\right]$ the molecular center behaves quite independently from the rest of the molecule and exhibits LDOS only in a small energy range.

All this suggests that in $\left[\left(\operatorname{talen}^{t-\mathrm{Bu}_{2}}\right) \mathrm{Cu}_{3}\right]$ there is no delocalization of electronic states across the central carbon ring, the molecular center rather appears as a discontinuity in the orbital distribution of the three salen subunits, which is compatible with the interpretation that the complex preserves its heteroradialene form when adsorbed on the $\mathrm{Au}(111)$ surface. In contrast, the observed delocalized LDOS for $\left[\left(\right.\right.$ talalen $\left.\left.^{t-\mathrm{Bu}_{2}}\right) \mathrm{Cu}_{3}\right]$, including the molecular center, is indicative of a fully aromatic central carbon ring, which is the key requirement for electronically coupling the metal centers to each other. Interestingly, also for this molecule this main characteristic feature seems to be preserved upon adsorption on $\mathrm{Au}(111)$. As this forms the basis for the spin-polarization mechanism $[37,38]$, we believe that also the adsorbed [(talalen $\left.\left.{ }^{t-\mathrm{Bu}_{2}}\right) \mathrm{Cu}_{3}\right]$ should exhibit an enhanced spin coupling compared to [(talen $\left.\left.{ }^{t-\mathrm{Bu}_{2}}\right) \mathrm{Cu}_{3}\right][27]$.

\section{Molecular electronic symmetry and switching}

We found further signs for a heteroradialene character in $\left[\left(\right.\right.$ talen $\left.\left.^{t-\mathrm{Bu}_{2}}\right) \mathrm{Cu}_{3}\right]$. Figure 5 shows topography images of two molecules taken at $+0.4 \mathrm{~V}$ [Fig. 5(a)] and $+2.4 \mathrm{~V}$ [Fig. 5(b)]. 

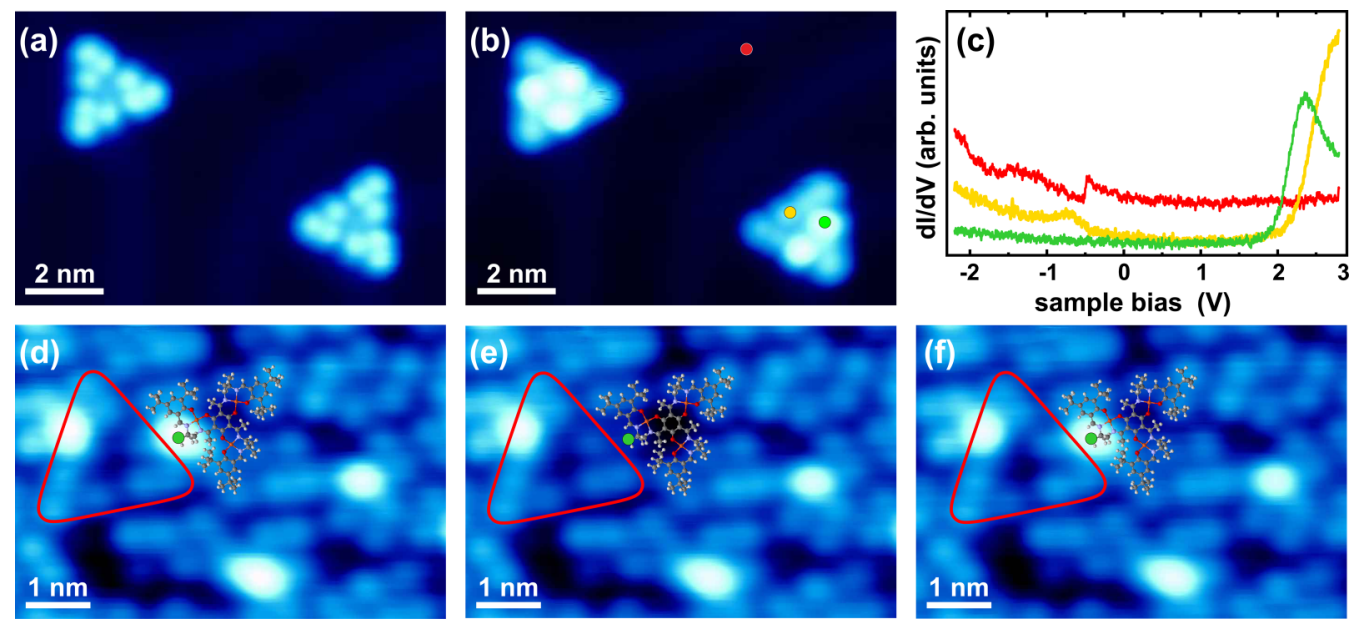

FIG. 5. (a) STM image of two [(talen $\left.\left.{ }^{t-\mathrm{Bu}_{2}}\right) \mathrm{Cu}_{3}\right]$ molecules taken at $0.4 \mathrm{~V}$. (b) When imaged at $2.4 \mathrm{~V}$, the right molecule appears asymmetric. (c) $d I / d V$ spectra [taken at the positions indicated in (b)] reveal a significantly different electronic structure for the dim vs bright salen arms. For comparison, the bare $\mathrm{Au}(111)$ spectrum is shown (offset for better clarity). (d)-(f) Sequence of STM images acquired on a monolayer of $\left[\left(\operatorname{talen}^{t-\mathrm{Bu}_{2}}\right) \mathrm{Cu}_{3}\right]$ molecules that shows reproducible tip-induced switching from the asymmetric to symmetric and back to the asymmetric shape after applying a voltage pulse at the marked position (imaging parameters: $1 \mathrm{~V}, 100 \mathrm{pA} ; 6.7 \times 4.5 \mathrm{~nm}^{2}$ ).

While both molecules look identical and threefold symmetric at low voltages, at higher positive bias the right molecule appears asymmetric with only two bright and one dim lobe at the periphery. From the comparison of the two topography images we conclude that the asymmetry is not a tip artifact and cannot stem from structural changes (e.g., rotation of a tert-butyl group), which would be visible at all voltages, but it must be electronic in origin. Indeed, $d I / d V$ spectra reveal that this asymmetry is accompanied by a severe change of the electronic structure of the specific salen arms: the $-0.8 \mathrm{~V}$ peak disappears and the steep $d I / d V$ increase above $2 \mathrm{~V}$ shifts down significantly, revealing a peak at $+2.3 \mathrm{~V}$. A recent study of a triplecobaltsalophene molecule on $\mathrm{Au}(111)$ suggests that electronic inhomogeneities may arise from different local adsorption sites of the three metal centers [28]. To verify this possibility, we also studied a highly ordered close-packed monolayer of [(talen $\left.\left.{ }^{t-\mathrm{Bu}_{2}}\right) \mathrm{Cu}_{3}\right]$ [Fig. 5(d)] [15]. Out of more than 200 molecules studied, none initially showed an asymmetry. Only when scanning at high positive samplebias voltages, we also observed that some molecules were asymmetric.

Moreover, we were able to reproducibly switch single molecules from the asymmetric [Fig. 5(d)] to the symmetric state [Fig. 5(e)] and back [Fig. 5(f)]. For this we positioned the STM tip over the specific position and ramped the bias voltage to about $+2.5 \mathrm{~V}$. Due to the close-packed nature of the monolayer, we can rule out that the asymmetry is caused by a change of the local adsorption sites of the metal centers with respect to substrate atoms. Furthermore, the reversibility of the switching event also rules out the possibility of tip-induced dissociation effects such as local dehydrogenation [39-41], which would be irreversible under cryogenic UHV conditions. We point out that the switching only occurs when the applied voltage is sufficiently large for electrons to resonantly tunnel into the unoccupied state of the molecule. While the exact nature of this reversible asymmetry remains to be uncovered, a possible scenario for this is a local modification of redox state of the molecule: if indeed the three $\mathrm{Cu}$-salen arms are not electronically well coupled via the central carbon ring, either an additional electron could be localized on or an electron can be transferred off one of the three $\mathrm{Cu}$-salen arms without any impact on the other $\mathrm{Cu}$-salen subunits. This charge transfer would be most likely at the $\mathrm{Cu}$ sites, either reducing the $\mathrm{Cu}^{\mathrm{II}}$ to $\mathrm{Cu}^{\mathrm{I}}$ or oxidizing it to $\mathrm{Cu}^{\mathrm{III}}$. This is in accordance with the electrochemical analysis of [(talen $\left.\left.{ }^{t-\mathrm{Bu}_{2}}\right) \mathrm{Cu}_{3}\right]$ [25], which provides a reversible metal-centered change of the redox state. Different metalcentered oxidation states have also been observed for $\mathrm{Cu}$-salen molecules in an electrochemical environment [42]. In our case, we believe that such a stabilization of different charge states on one of the three salen subunits might be possible due to the bulky tert-butyl groups decoupling the $\mathrm{Cu}$ centers from the $\mathrm{Au}(111)$ substrate.

In contrast, we observed neither asymmetries nor switching for any of the (in total eight) studied [(talalen $\left.\left.{ }^{t-\mathrm{Bu}_{2}}\right) \mathrm{Cu}_{3}\right]$ molecules, even when imaged at high bias voltages around $+2 \mathrm{~V}$. This can easily be understood from the orbital distribution of the molecule. If indeed the central carbon ring exhibits a delocalized $\pi$-electron system, as indicated in our the $d I / d V$ maps, it causes an electronic coupling of all three salen subunits in [(talalen $\left.\left.{ }^{t-\mathrm{Bu}_{2}}\right) \mathrm{Cu}_{3}\right]$. Hence, it is very unlikely to stabilize an additional charge on just one salen subunit. In this respect, the very different asymmetry and switching observations for $\left[\left(\operatorname{talen}^{t-\mathrm{Bu}_{2}}\right) \mathrm{Cu}_{3}\right]$ vs $\left[\left(\right.\right.$ talalen $\left.\left.^{t-\mathrm{Bu}_{2}}\right) \mathrm{Cu}_{3}\right]$ provide an additional support for our interpretation that, even when adsorbed on $\mathrm{Au}(111)$, the central carbon ring of $\left[\left(\operatorname{talen}^{t-\mathrm{Bu}_{2}}\right) \mathrm{Cu}_{3}\right]$ has a heteroradialene character, while that of [(talalen $\left.{ }^{t-\mathrm{Bu}_{2}}\right) \mathrm{Cu}_{3}$ ] exhibits a delocalized electron system as is necessary for optimized spin coupling within the framework of the spin-polarization mechanism.

\section{CONCLUSION}

In summary, we rationally designed a new building-block molecule $\left[\left(\right.\right.$ talalen $\left.\left.^{t-\mathrm{Bu}_{2}}\right) \mathrm{Cu}_{3}\right]$ for the class of $\left[\mathrm{Mn}_{6}^{\mathrm{III}} \mathrm{M}^{\mathrm{III}}\right]^{3+}$ single-molecule magnets. Spectrochemical analysis shows 
that, compared to $\left[\left(\operatorname{talen}^{t-\mathrm{Bu}_{2}}\right) \mathrm{Cu}_{3}\right]$, the aromaticity of the central carbon ring is stabilized. As the spin coupling in this class of SMMs is based on the spin-polarization mechanism, which requires a delocalized aromatic $\pi$ system on the central carbon ring, a suppression of the heteroradialene formation should lead to an improved intramolecular spin coupling, which we indeed found in our susceptibility measurements. STM experiments on single adsorbed molecules, including $d I / d V$ spectra and maps as well as the analysis of switchable asymmetries, support that indeed the central carbon ring in $\left[\left(\operatorname{talen}^{t-\mathrm{Bu}_{2}}\right) \mathrm{Cu}_{3}\right]$ is best described as a heteroradialenelike structure with exocyclic double bonds that represent a discontinuity in the intramolecular electronic coupling, while [(talalen $\left.{ }^{t-\mathrm{Bu}_{2}}\right) \mathrm{Cu}_{3}$ ] exhibits a delocalized aromatic $\pi$ system. As this electronic feature, which is important for the spin-polarization mechanism, is obviously preserved upon adsorption on the $\mathrm{Au}(111)$ surface, we believe that also the enhanced spin coupling may be preserved for adsorbed molecules. Hence, our results are a promising step toward systematic single-molecule studies of adsorbed SMMs.

In conclusion, our combined chemical synthesis and STM/STS study shows that a careful analysis of the chemical structure of SMM building blocks and its correlation to the magnetic and local electronic properties allows us to identify what determines the coupling of spins in a molecular magnet. As the electronic character of the triplesalen-based molecules seems to be unaltered upon adsorption, we propose that also SMMs of the $\left[\mathrm{Mn}_{6}^{\mathrm{III}} \mathrm{M}^{\mathrm{III}}\right]^{3+}$ family may retain their properties upon adsorption. This would be an important step toward a systematic study and improvement of surface-supported SMMs. Moreover, while for many other SMMs an STM-based analysis is challenging due to difficulties in identifying the adsorption geometry of the bulky molecules, an advantage of the triplesalen-based family presented here is their planar molecular structure, making them highly accessible to a probe tip and thus an ideal model platform to study molecular magnetism via scanning probe experiments. We are convinced that our findings also pave the way for an improvement of the rational design strategy for SMMs, because synthetic approaches to enhance the spin coupling can be complemented by the highly resolved studies of intramolecular properties on a surface and the impact of molecule-surface interactions.

\section{ACKNOWLEDGMENTS}

We thank the Deutsche Forschungsgemeinschaft (DFG) for financial support through the Research Unit FOR 945 (Project P1) as well as Project No. WE 4104/2-1. J.D. acknowledges support by the Studienstiftung des Deutschen Volkes.
[1] R. Sessoli, D. Gatteschi, A. Caneschi, and M. A. Novak, Nature (London) 365, 141 (1993).

[2] D. Gatteschi and R. Sessoli, Angew. Chem. Int. Ed. 42, 268 (2003).

[3] N. Ishikawa, M. Sugita, and W. Wernsdorfer, Angew. Chem. Int. Ed. 44, 2931 (2005).

[4] T. Glaser, M. Heidemeier, T. Weyhermuller, R. D. Hoffmann, H. Rupp, and P. Müller, Angew. Chem. Int. Ed. 45, 6033 (2006).

[5] C. J. Milios, A. Vinslava, W. Wernsdorfer, S. Moggach, S. Parsons, S. P. Perlepes, G. Christou, and E. K. Brechin, J. Am. Chem. Soc. 129, 2754 (2007).

[6] J. D. Rinehart, M. Fang, W. J. Evans, and J. R. Long, Nat. Chem. 3, 538 (2011).

[7] K. R. Meihaus and J. R. Long, J. Am. Chem. Soc. 135, 17952 (2013).

[8] M. N. Leuenberger and D. Loss, Nature (London) 410, 789 (2001).

[9] L. Bogani and W. Wernsdorfer, Nat. Mater. 7, 179 (2008).

[10] S. Thiele, F. Balestro, R. Ballou, S. Klyatskaya, M. Ruben, and W. Wernsdorfer, Science 344, 1135 (2014).

[11] M. Mannini, F. Pineider, C. Danieli, F. Totti, L. Sorace, P. Sainctavit, M. A. Arrio, E. Otero, L. Joly, J. C. Cezar, A. Cornia, and R. Sessoli, Nature (London) 468, 417 (2010).

[12] S. Stepanow, J. Honolka, P. Gambardella, L. Vitali, N. Abdurakhmanova, T. C. Tseng, S. Rauschenbach, S. L. Tait, V. Sessi, S. Klyatskaya, M. Ruben, and K. Kern, J. Am. Chem. Soc. 132, 11900 (2010).

[13] S. Kahle, Z. T. Deng, N. Malinowski, C. Tonnoir, A. Forment-Aliaga, N. Thontasen, G. Rinke, D. Le, V. Turkowski,
T. S. Rahman, S. Rauschenbach, M. Ternes, and K. Kern, Nano Lett. 12, 518 (2012).

[14] P. Erler, P. Schmitt, N. Barth, A. Irmler, S. Bouvron, T. Huhn, U. Groth, F. Pauly, L. Gragnaniello, and M. Fonin, Nano Lett. 15, 4546 (2015).

[15] J. Donner, J. P. Broschinski, T. Glaser, and D. Wegner, J. Phys. Chem. C 119, 28660 (2015).

[16] L. Bogani, L. Cavigli, M. Gurioli, R. L. Novak, M. Mannini, A. Caneschi, F. Pineider, R. Sessoli, M. Clemente-Leon, E. Coronado, A. Cornia, and D. Gatteschi, Adv. Mater. 19, 3906 (2007).

[17] M. Mannini, F. Pineider, P. Sainctavit, L. Joly, A. FraileRodriguez, M. A. Arrio, C. C. D. Moulin, W. Wernsdorfer, A. Cornia, D. Gatteschi, and R. Sessoli, Adv. Mater. 21, 167 (2009).

[18] N. Tsukahara, K. I. Noto, M. Ohara, S. Shiraki, N. Takagi, Y. Takata, J. Miyawaki, M. Taguchi, A. Chainani, S. Shin, and M. Kawai, Phys. Rev. Lett. 102, 167203 (2009).

[19] J. Brede, N. Atodiresei, S. Kuck, P. Lazic, V. Caciuc, Y. Morikawa, G. Hoffmann, S. Blugel, and R. Wiesendanger, Phys. Rev. Lett. 105, 047204 (2010).

[20] S. Stepanow, P. S. Miedema, A. Mugarza, G. Ceballos, P. Moras, J. C. Cezar, C. Carbone, F. M. F. de Groot, and P. Gambardella, Phys. Rev. B 83, 220401(R) (2011).

[21] C. Wäckerlin, F. Donati, A. Singha, R. Baltic, S. Rusponi, K. Diller, F. Patthey, M. Pivetta, Y. Lan, S. Klyatskaya, M. Ruben, H. Brune, and J. Dreiser, Adv. Mater. 28, 5195 (2016).

[22] J. A. J. Burgess, L. Malavolti, V. Lanzilotto, M. Mannini, S. C. Yan, S. Ninova, F. Totti, S. Rolf-Pissarczyk, A. Cornia, R. Sessoli, and S. Loth, Nat. Commun. 6, 8216 (2015). 
[23] T. Glaser, Chem. Commun. 47, 116 (2011).

[24] T. Glaser, V. Hoeke, K. Gieb, J. Schnack, C. Schröder, and P. Müller, Coordin. Chem. Rev. 289-290, 261 (2015).

[25] T. Glaser, M. Heidemeier, J. B. H. Strautmann, H. Bögge, A. Stammler, E. Krickemeyer, R. Huenerbein, S. Grimme, E. Bothe, and E. Bill, Chem. Eur. J. 13, 9191 (2007).

[26] S. Hill, S. Datta, J. Liu, R. Inglis, C. J. Milios, P. L. Feng, J. J. Henderson, E. del Barco, E. K. Brechin, and D. N. Hendrickson, Dalton Trans. 39, 4693 (2010).

[27] T. Glaser, Coordin. Chem. Rev. 257, 140 (2013).

[28] M. Bazarnik, B. Bugenhagen, M. Elsebach, E. Sierda, A. Frank, M. H. Prosenc, and R. Wiesendanger, Nano Lett. 16, 577 (2016).

[29] See Supplemental Material at http://link.aps.org/supplemental/ 10.1103/PhysRevB.95.165441 for details concerning the design strategy and synthesis as well as the spectrochemical analysis.

[30] The program package JulX was used for spin-Hamiltonian simulations and fitting of the data by a full-matrix diagonalization approach (E. Bill, unpublished results).

[31] See Supplemental Material at http://link.aps.org/supplemental/ 10.1103/PhysRevB.95.165441 for computional details.

[32] J. K. Gimzewski, C. Joachim, R. R. Schlittler, V. Langlais, H. Tang, and I. Johannsen, Science 281, 531 (1998).

[33] F. Moresco, L. Gross, M. Alemani, K. H. Rieder, H. Tang, A. Gourdon, and C. Joachim, Phys. Rev. Lett. 91, 036601 (2003).
[34] See Supplemental Material at http://link.aps.org/supplemental/ 10.1103/PhysRevB.95.165441 for details on sample preparation and STM/STS experiments.

[35] X. H. Lu, M. Grobis, K. H. Khoo, S. G. Louie, and M. F. Crommie, Phys. Rev. Lett. 90, 096802 (2003).

[36] P. R. Ewen, J. Sanning, N. L. Doltsinis, M. Mauro, C. A. Strassert, and D. Wegner, Phys. Rev. Lett. 111, 267401 (2013).

[37] C. Yuste, J. Ferrando-Soria, D. Cangussu, O. Fabelo, C. RuizPerez, N. Marino, G. De Munno, S. E. Stiriba, R. Ruiz-Garcia, J. Cano, F. Lloret, and M. Julve, Inorg. Chim. Acta 363, 1984 (2010).

[38] M. Castellano, F. R. Fortea-Perez, A. Bentama, S. E. Stiriba, M. Julve, F. Lloret, G. De Munno, D. Armentano, Y. L. Li, R. Ruiz-Garcia, and J. Cano, Inorg. Chem. 52, 7645 (2013).

[39] A. D. Zhao, Q. X. Li, L. Chen, H. J. Xiang, W. H. Wang, S. Pan, B. Wang, X. D. Xiao, J. L. Yang, J. G. Hou, and Q. S. Zhu, Science 309, 1542 (2005).

[40] N. Baadji, S. Kuck, J. Brede, G. Hoffmann, R. Wiesendanger, and S. Sanvito, Phys. Rev. B 82, 115447 (2010).

[41] B. W. Heinrich, G. Ahmadi, V. L. Müller, L. Braun, J. I. Pascual, and K. J. Franke, Nano Lett. 13, 4840 (2013).

[42] P. A. Farias and M. B. Bastos, Int. J. Electrochem. Sci. 4, 458 (2009). 